\title{
Gonad morphology, oocyte development and spawning cycle of the calanoid copepod Acartia clausi
}

\author{
Sonja M. Eisfeld · Barbara Niehoff
}

Received: 28 May 2006/Revised: 19 February 2007/Accepted: 19 February 2007/Published online: 16 March 2007

(C) Springer-Verlag and AWI 2007

\begin{abstract}
Information on gonad morphology and its relation to basic reproductive parameters such as clutch size and spawning frequency is lacking for Acartia clausi, a dominant calanoid copepod of the North Sea. To fill this gap, females of this species were sampled at Helgoland Roads from mid March to late May 2001. Gonad structure and oogenesis were studied using a combination of histology and whole-body-analysis. In addition, clutch size and spawning frequency were determined in incubation experiments, during which individual females were monitored at short intervals for 8 and $12 \mathrm{~h}$, respectively. The histological analysis revealed that the ovary of A. clausi is w-shaped with two distinct tips pointing posteriorly. It is slightly different from that of other Acartia species and of other copepod taxa. From the ovary, two anterior diverticula extend into the head region, and two posterior diverticula extend to the genital opening in the abdomen. Developing oocytes change in shape and size, and in the appearance of the nucleus and the ooplasm. Based on these morphological characteristics, different oocyte development stages (OS) were identified. Mitotically dividing oogonia and young oocytes (OS 0 ) were restricted to the ovary, whereas vitellogenic oocytes (OS 1-4) were present in the diverticula. The development stage of the oocytes increased with distance to the ovary in both, anterior and posterior diverticula. Most advanced oocytes were situated ventrally, and their number varied between 1 and 18, at a
\end{abstract}

Communicated by H.-D. Franke.

S. M. Eisfeld · B. Niehoff ( $\square)$

Marine Animal Ecology,

Alfred Wegener Institute for Polar and Marine Research,

27568 Bremerhaven, Germany

e-mail: bniehoff@awi-bremerhaven.de median of 4. All oocyte development stages co-occur indicating that oogenesis in A. clausi is a continuous process. These morphological features reflect the reproductive traits of this species. In accordance with the low numbers of mature oocytes in the gonads, females usually produced small clutches of one to five eggs. Clutches were released throughout the entire observation period at intervals of 90 min (median) resulting in mean egg production rates of 18-28 eggs female ${ }^{-1}$ day $^{-1}$.

Keywords Acartia clausi - Egg production . Gonad morphology $\cdot$ Oogenesis $\cdot$ Spawning cycle

\section{Introduction}

The calanoid copepod Acartia clausi is a key species in the zooplankton community of the North Sea. Together with Centropages typicus, Temora longicornis and Pseudocalanus elongatus, A. clausi contributes up to $85 \%$ to the zooplankton biomass (Hickel 1975; Fransz et al. 1991). Many aspects of its reproductive biology have been investigated, in particular, the relation of egg production, feeding conditions and temperature (e.g. Uye 1981; Ianora and Scotto di Carlo 1988; Ianora and Buttino 1990; Tiselius et al. 1991; Hay 1995; Prestidge et al. 1995). Laboratory experiments revealed that both food quality (Donaghay and Small 1979; Ianora et al. 1996; Dutz 1998; Mayzaud et al. 1998) and quantity (Dagg 1977; Uye 1981; Ianora and Scotto di Carlo 1988) influence egg production rates. Halsband and Hirche (2001) show that in the North Sea temperature rather than feeding conditions affected egg production rates, whereas Hay (1995) found that egg production is neither related to temperature nor to chlorophyll $a$ concentration. The time series by Halsband and 
Hirche (2001) indicates that A. clausi spawns from February through September in the North Sea with maximum rates during summer. In winter egg production ceases, and in contrast to populations in the Pacific, apparently no resting eggs are produced (Engel and Hirche 2004).

Detailed studies on gonad morphology and oocyte development as in Calanus finmarchicus (Hilton 1931; Niehoff and Hirche 1996), Centropages typicus (Arnaud et al. 1982), and Temora stylifera (Razouls 1974; Razouls et al. 1986) are essential to fully understand a specieś reproductive physiology. Such studies are lacking for $A$. clausi. Ianora and Scotto di Carlo (1988) described the seasonal changes in gonad appearance. Norrbin (2001) presented changes in gonad morphology during the transition from diapause to activity focussing on early oocytes of the related species A. longiremis. Eckelbarger and Blades-Eckelbarger (2005) compared the oogenesis among calanoid copepods including $A$. tonsa, however, the authors did not describe the gonad morphology. Gonad morphology is often closely related to reproductive traits such as clutch size and spawning frequency (e.g. Calanus: Plourde and Runge 1993; Niehoff and Runge 2003; Pseudocalanus: Niehoff 2003; Temora: Razouls 1974). In A. clausi, however, neither clutch size nor spawning frequency has yet been determined precisely. Halsband and Hirche (2001) observed that $A$. clausi deposits "low numbers of eggs" at intervals of a few hours. Uye (1981) mentioned that $A$. clausi and A. steueri lay eggs more or less continuously throughout the day. Acartia tonsa deposits eggs " in batches or strings, one egg appearing every few seconds, an event repeated several times throughout the day" (Dagg 1977). Hence, the present study aims (1) to describe the gonad and oocyte morphology of spawning female $A$. clausi, (2) to determine the clutch size and spawning frequency and (3) to relate gonad morphology to reproductive traits. The morphology of the female gonad was studied using both light-microscopy and whole-body-analysis. To determine clutch size and spawning frequency, incubation experiments were conducted in which individual females were monitored in short intervals $(20-30 \mathrm{~min})$ for the release of eggs.

\section{Methods}

The copepods were collected at Helgoland Roads (N 54 $11^{\prime}$, E $7^{\circ} 53^{\prime}$ ) in the North Sea in spring 2001. Helgoland is a small island, $60 \mathrm{~km}$ northwest off the German coast, and is divided into the main island Helgoland and the dune. Helgoland Roads denotes the 600 to $800-\mathrm{m}$ wide channel between Helgoland and the dune. It is characterised by low depths of 4 to 12 meters and marked tidal currents (Husemann 1992; Plate 1992).
Sampling

Zooplankton was collected on March 26 and 27, April 23 and 25, and May 31, with a plankton net (mesh size $280 \mu \mathrm{m}$ ) which was towed horizontally for $20 \mathrm{~min}$ at a speed of two knots. Onboard, the samples were immediately diluted in surface seawater and transported to the Biological Station on Helgoland within 30 min after capture. On arrival, live A. clausi females and males were gently sorted under a binocular microscope and placed in 11 plastic bottles containing pre-screened seawater. The copepods were then transported in cooling boxes to the Alfred Wegener Institute (Bremerhaven). Ambient seawater temperature at capture was approx. $5^{\circ} \mathrm{C}$ in April and $7^{\circ} \mathrm{C}$ in May. During the transports the temperature did not exceed $8^{\circ} \mathrm{C}$, thus females were exposed to a maximum increase in temperature of $3^{\circ} \mathrm{C}$.

\section{Light microscopy of gonads and oocytes}

To describe the internal structure of the gonad and the oocyte development, females were preserved for light microscopy for $1 \mathrm{~h}$ at $4^{\circ} \mathrm{C}$ in $1 \%$ paraformaldehyde and $1.5 \%$ glutaraldehyde (Karnovsky 1965) in $0.1 \mathrm{M}$ sodium cacodylate buffer immediately after sorting or experiments. For rapid penetration of the fixative, the antennae, the abdominal segments and some limbs were cut off. The tissue was dehydrated using standard ethanol series and then embedded in Technovit 7100 (Heraeus Kulzer). Thin sections of $3 \mu \mathrm{m}$ were cut with a microtome (ReichertJung), stained either with Richardson Blue or hematoxyline and eosin, and examined under a microscope. Photographs were taken with a digital camera (Axio Cam HRc, Zeiss). Five oocyte developmental stages (OS 0-4) were classified according to size, appearance of the ooplasm and nuclear structures following Niehoff and Hirche (1996) and Niehoff (2003). In 40 females, the size of at least 100 oocytes each at OS 1,2 and 3 was measured using micrometer lens. In OS 1, the diameter of the oocytes was determined, whereas maximum width and length were measured in OS 2 and OS 3 as these oocytes are irregularly shaped. Due to their strong deformation oocytes in OS 4 were not measured.

\section{Experiments}

Upon arrival in Bremerhaven, females and males (ratio of 2:1) were transferred into 21 glass beakers containing prefiltered $(0.45 \mu \mathrm{m})$ seawater. They were kept at $8^{\circ} \mathrm{C}$ in a 12:12 $\mathrm{h}$ light/dark cycle. The water was gently bubbled to prevent anoxia and to induce some turbulence. Once a week, the copepods were gently transferred into fresh medium. For at least 7 days, the copepods were fed ad 
libitum with a suspension of the diatoms Thalassiosira weissflogii (13-14 $\mu \mathrm{m}$ diameter) and Skeletonema costatum (4-9 $\mu \mathrm{m}$ diameter), and the flagellate Scrippsiella trochoidea ( $24 \mu \mathrm{m}$ length and $20 \mu \mathrm{m}$ width). The algae were cultured in $\mathrm{f} / 2$ medium at $12^{\circ} \mathrm{C}$ under permanent light and maintained in exponential growth by dilution in fresh medium at least twice a week.

To determine clutch size and spawning frequency, 60 (April 11) or 120 (April 10, May 2-4) females were taken from the 21 beakers and placed individually in cell wells (10 ml) containing filtered seawater and $2 \mathrm{ml}$ Thalassiosira weissflogii suspension. For 8 and $12 \mathrm{~h}$, respectively, the cell wells were checked at 20-30 min intervals, and the eggs were counted and removed. This experiment was conducted five times in order to account for variations due to the time of capture (April vs. May) and the duration of the laboratory period. To describe the gonad morphology after a spawning event, a total of 20 females were studied. Five females were preserved in the fixation solution after Karnovsky (1965) and analysed by light microscopy. The other 15 females were preserved in $4 \%$ formaldehyde and their gross gonad morphology was studied under a binocular microscope $(80 \times)$.

Calculation of clutch size, spawning frequency and egg production rate

The clutch size is given by the number of eggs released during one discrete spawning event. This parameter is difficult to determine for females with multiple spawning within a short period of time $(<8 \mathrm{~h})$ as eggs of subsequent clutches may mistakenly be attributed to a single clutch. Direct observations of spawning females showed that one spawning event lasted only a few minutes and was usually followed by a period more than $30 \mathrm{~min}$ without egg release. Hence, we defined clutch size as the number of egg released between subsequent controls (interval 20$30 \mathrm{~min}$ ). The interval of clutch production was defined as the time between two controls at which eggs were found.

As the frequency distribution of both clutch size and interval was not normally distributed but strongly biased for low values, the median was used to describe the general tendencies of the data. To give a measure for the variability of the data, we used the median absolute deviation (MAD), which is the median of the set of differences between each data point and the median of the data.

To compare our data with those of other studies, mean daily egg production rates (EPR, eggs female ${ }^{-1} \mathrm{~d}^{-1}$ ) were calculated:

$\mathrm{EPR}=\frac{1}{n_{\mathrm{F}}} \sum_{i=1}^{n_{\mathrm{F}}} n_{\mathrm{eggs}} * \frac{24 h}{h_{\mathrm{obs}}}$ with $i=1,2,3, \ldots, n_{\mathrm{F}} ; n_{\mathrm{F}}=$ number of incubated females, $h_{\mathrm{obs}}=$ duration of the observation (h).

As some females did not release eggs during the observation period, we also calculated the egg production rate of spawning females $\left(\mathrm{EPR}_{\mathrm{SF}}\right)$ :

$\mathrm{EPR}_{\mathrm{SF}}=\frac{1}{n_{\mathrm{SF}}} \sum_{i=1}^{n_{\mathrm{SF}}} n_{\mathrm{eggs}} * \frac{24 h}{h_{\mathrm{obs}}}$

with $i=1,2,3, \ldots, n_{\mathrm{F}} ; n_{\mathrm{F}}=$ number of incubated females, $h_{\mathrm{obs}}=$ duration of the observation (h).

All calculations were performed using STAT View 5.1 for Apple Macintosh.

\section{Results}

Gonad structure and oocyte distribution

The female gonad of $A$. clausi consisted of a dorsally laying ovary with two anterior diverticula extending into the head region, and two posterior diverticula which extended ventro-laterally to the genital opening in the first abdominal segment. The ovary was w-shaped with two separated tips pointing backwards (Fig. 1a, b). As in the ovary of Calanus finmarchicus (Hilton 1931), different zones can be distinguished (Fig. 1c). Germ cells were located at the tip of the ovary. Anterior to the germ cells, there were mitotically dividing oogonia (multiplication zone), followed by oocytes with chromosome structures characteristic of the early stages of prophase I (synapsis zone). The adjacent layers of young oocytes represented progressive growth stages (growth zone). Germ cells, oogonia and oocytes in early stages of prophase I were restricted to the ovary. From the growth zone of the ovary, the oocytes passed into the diverticula where they completed oogenesis (Fig. 1a, f). In the anterior diverticula, the oocyte size and development stage increased from the ovary towards the head region, and from dorsal to ventral. From the head region, mature oocytes seemed to pass ventrally to the genital opening. In the posterior diverticula, the oocyte development advanced from the ovary towards the abdomen, and also from dorsal to ventral with the most mature oocytes situated ventrally close to the genital opening.

Oocyte development stages

During oogenesis, the morphology of the oocytes changed due to cell growth, modification of the nucleus and the incorporation of lipid and yolk vesicles. According to 
Fig. 1 Female gonad and oocyte development stages of Acartia clausi. a Overview of a gonad showing the ovary with anterior $(D V a)$ and posterior $(D V p)$ diverticula (longitudinal section), b ovary (longitudinal section), c ovary (longitudinal section) with germ cells $(G C)$, multiplication zone (1), synapsis zone (2) and growth zone (3), d oocyte development stage 1 (OS 1), e oocyte development stage 2 (OS 2), f succession of oocytes in oocyte development stage 3 in the anterior diverticula (OS $3 \mathrm{e}=$ early, OS $3 \mathrm{a}=$ advanced, OS $31=$ late), g oocyte development stage 4 (OS 4) with chromosomes situated on the equatorial plate of metaphase I. $L V$ lipid vesicles, $M$ muscle, $N$ nucleus, $\mathrm{Nu}$ nucleolus, $\mathrm{Ov}$ ovary, $Y$ yolk vesicles. Scale: a, f $50 \mu \mathrm{m}$; b, c, d, e $20 \mu \mathrm{m} ; \mathbf{g} 10 \mu \mathrm{m}$
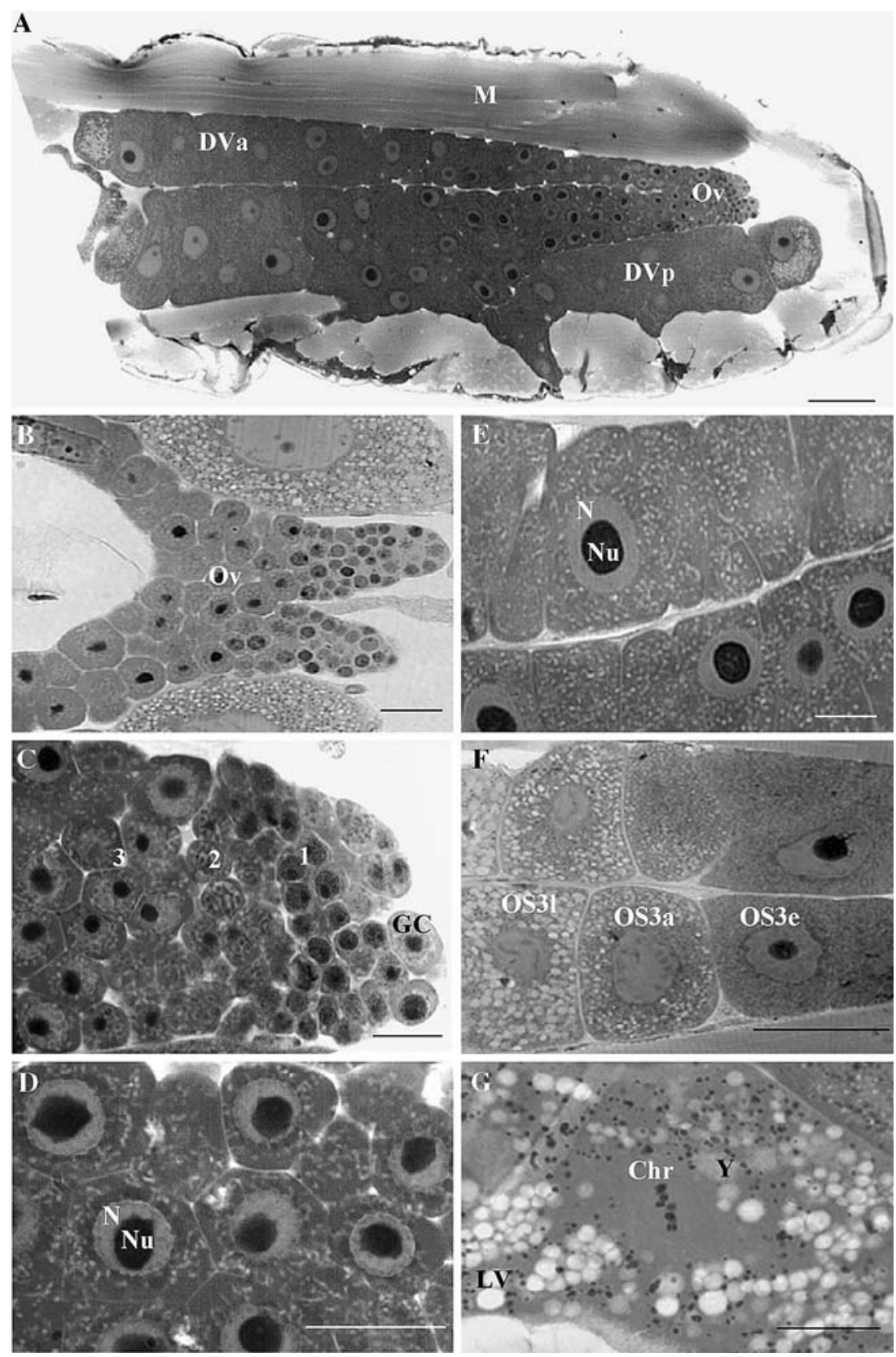

Niehoff and Hirche (1996) and Niehoff (2003), five oocyte developmental stages were distinguished.

OS 0: Oogonia and previtellogenic oocytes in early stages of meiosis (leptotene/zygotene/pachytene; Fig. 1b, c).

OS 1: Young oocytes were hexagonal or polygonal measuring $22.4 \pm 5.0 \mu \mathrm{m}$ in diameter. The nucleus contained a central nucleolus occupying most of the cell, and was surrounded by a complete membrane. The ooplasm of the young oocytes contained only a few yolk vesicles, which were distributed throughout the ooplasm (Fig. 1c).
OS 2: Half grown oocytes were oval and had a length of $52.8 \pm 14.6 \mu \mathrm{m}$ and a width of $34.0 \pm 9.5 \mu \mathrm{m}$. Nucleus and nucleolus were unchanged. Around the nucleolus chromatin structures were visible as long thin threads, and the ooplasm was interspersed with yolk vesicles (Fig. 1d). In some oocytes, follicle cells were visible.

OS 3: Oocyte size in OS 3 increased from $69.8 \pm$ $15.1 \mu \mathrm{m}$ length and $48.2 \pm 11.5 \mu \mathrm{m}$ width in early OS 3 to $98.2 \pm 18.8 \mu \mathrm{m}$ length and $62.3 \pm 13.3 \mu \mathrm{m}$ width in late OS 3 (Fig. 1e). In early OS 3, the nuclear membrane started to break down. Lipid and yolk vesicles were equally distributed in the ooplasm (Fig. 1f). In advanced OS 3, the 
nucleus was irregular in shape and the nuclear membrane was partially dissolved. Threads of chromosomes were visible in the cytoplasm. Number and size of lipid and yolk vesicles had increased. In late OS 3 , the nuclear membrane was largely dissolved and the nucleus migrated to the periphery of the cell. Chromosomes were visible as short, thick threads or rings around the dissolving nucleolus. The ooplasm was densely filled with vesicles containing yolk or lipids. Late OS 3 were rarely observed in the diverticula of A. clausi, which indicates a rapid transition development from late OS 3 to OS 4 .

OS 4: Mature oocytes were irregular in shape; size measurements were thus not possible (see Methods). The nuclear membrane and the nucleoli were completely dissolved. The chromosomes formed the equatorial plate of the metaphase I (Fig. 1g). The ooplasm contained numerous large lipid and yolk vesicles. In this stage, oocytes were released.

Gonad morphology in relation to the spawning cycle

Gonads of mature A. clausi contained all oocyte development stages including intermediate ones. The number of cells in distinct stages was always low. Counting oocytes in early, advanced and late OS 3 and OS 4 revealed that no more than eight oocytes were in the same stage. Apparently, it was only few oocytes, which developed synchronously. After spawning, the gonad morphology was not visibly different from that prior to spawning. In females preserved immediately after the egg release, all oocyte stages including OS 3 and OS 4 were found (Table 1). In the gonads of 12 out of 15 females studied macroscopically mature oocytes were visible; only three did not contain any mature oocytes.

Table 1 Oocyte development stages and numbers of oocytes in gonads of five Acartia clausi females preserved for light microscopy immediately after spawning

\begin{tabular}{lllllll}
\hline Female & OS 1 & OS 2 & \multicolumn{2}{l}{ OS 3 } & OS 4 \\
\cline { 3 - 6 } & & & Early & Advanced & Late & \\
\hline 1 & +++ & +++ & 6 & 4 & 0 & 0 \\
2 & +++ & +++ & 8 & 7 & 0 & 4 \\
3 & +++ & +++ & 7 & 3 & 2 & 4 \\
4 & ++ & ++ & 7 & 5 & 0 & 1 \\
5 & + & + & 8 & 6 & 0 & 0 \\
\hline
\end{tabular}

Numbers are given for oocytes in stages undergoing final development (OS 3 and 4). Younger oocytes (OS 1 and 2) were not counted but their numbers were roughly estimated: $+++=$ large number, $++=$ average number, $+=$ low number
Clutch size and spawning frequency

The observation of individual females at short intervals allowed determining clutch size and spawning frequency of A. clausi. Several spawning events were directly observed during which females released-about one to five eggs in 2-7 min. The release of a small batch of eggs was typically followed by a period of usually no more than $30 \mathrm{~min}$ without egg release. The number of eggs released within the 20-30 min between two observations was considered as a single clutch (see Methods). The interval until the first observation was approximately $1 \mathrm{~h}$ since the transfer of the females from beakers into cell wells took relatively long time. During this time, multiple spawning may have occurred and thus these data were excluded from the presentation of clutch sizes.

Clutch size and spawning frequency were monitored on five days for 12 (April 10, 11) or 8 h (May 2-4; Fig. 2). Between 78 and $90 \%$ of the females released eggs during the entire observation period of 8 and $12 \mathrm{~h}$, respectively, and more than $60 \%$ of these females spawned more than once. The proportion of spawning females at single controls varied from 5 to $30 \%$ in all experiments. During the $12 \mathrm{~h}$ incubation (April 10, 11), females produced on average four clutches (SD 1.9), and during the $8 \mathrm{~h}$ incubation 2.2-2.5 clutches (SD 1.3, May 2-4). To compare the production of clutches between the two sampling periods in April and May, the average clutch production during the first $8 \mathrm{~h}$ was calculated. In April, females produced more clutches within $8 \mathrm{~h}$ (April 10: 2.9, SD 1.4; April 11: 3.7, SD 1.5) than in May; this difference, however, is not statistically significant (Kolmogorov Smirnov Test $P>0.05$ ).

The individual variability of the clutch size was high in all experiments ranging from 1 to 19 eggs. The frequency distribution of clutch sizes showed that clutches with one egg were most frequent $(35.7 \%)$, clutches with two to five eggs occurred often with decreasing contribution [22\% (2 eggs) to $6 \%$ (5 eggs)], and clutches with more than five eggs were rare (Fig. 3a). The overall median clutch size was two eggs (MAD 1) as was the median in single experiments, except on 10 April where the median was three eggs clutch ${ }^{-1}$ (MAD 2). The median clutch size obtained from the single observations varied generally from one to five eggs clutch $^{-1}$ over the course of the incubations (Fig. 2). Clutch size did not change significantly with the sampling period or with the duration of the incubation (Kolmogorov Smirnov test, $P>0.05$; Table 2).

During the experiments, the eggs were released between intervals of $9-567 \mathrm{~min}$. Usually the time between to spawning events did not exceed 90 min (Fig. 3b), and only $20 \%$ of the intervals were longer than $180 \mathrm{~min}$. The median interval between two spawning events during the five experiments was 88 min (MAD 55). Between the 
Fig. 2 Frequency distribution of clutch size (a) and interspawning intervals (b) of Acartia clausi
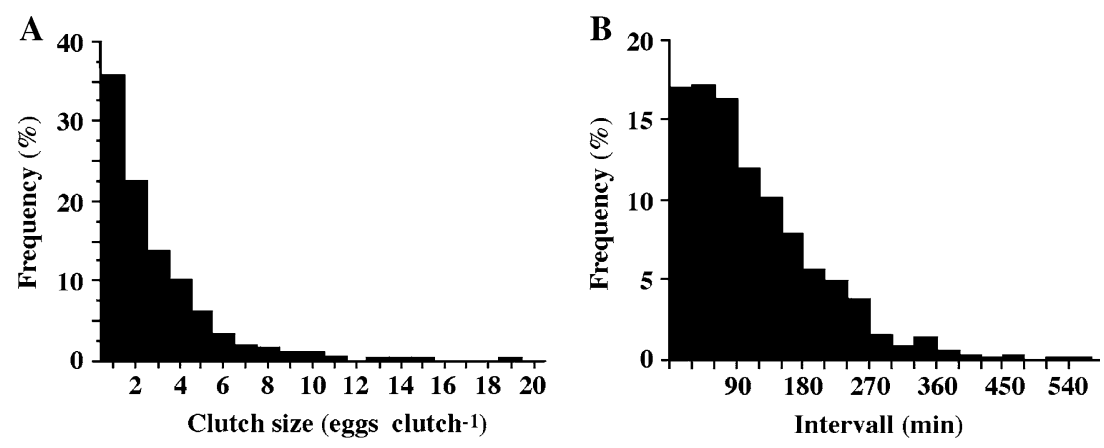

Fig. 3 Median clutch size of Acartia clausi over 8 or 12 h of incubation during five experiments (a-e). The bars present the median absolute deviation $(M A D)$
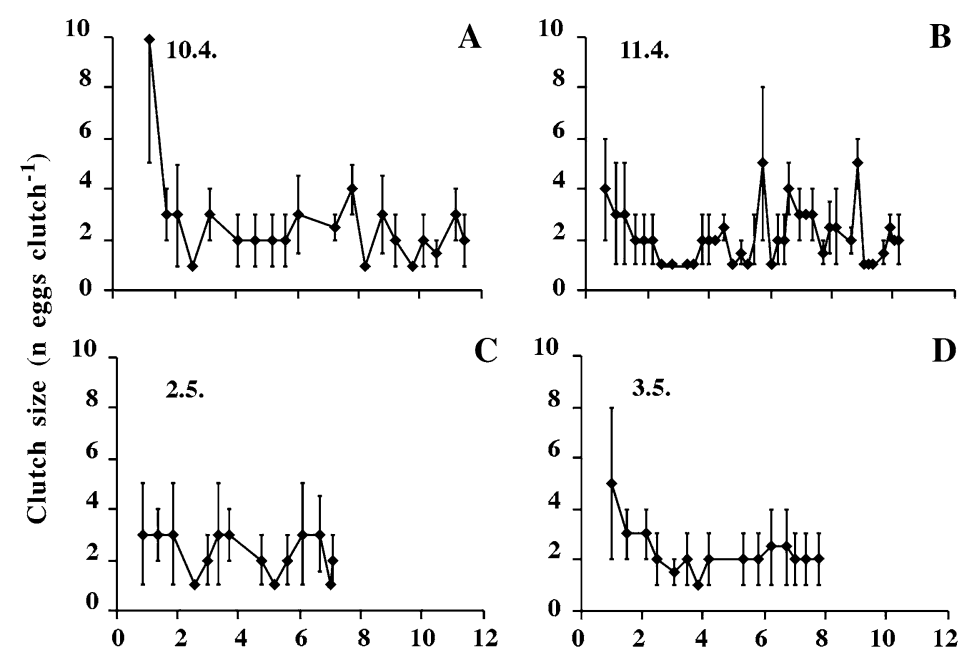

B

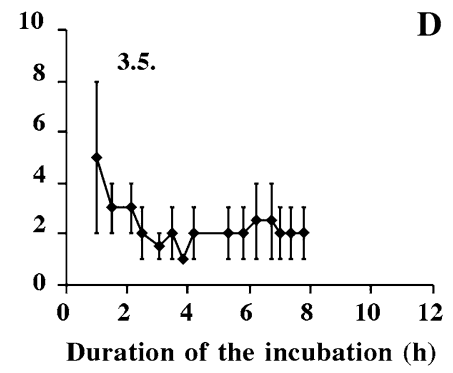

F

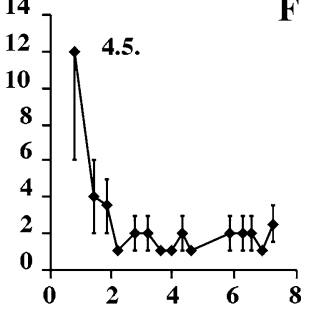

experiments, the mean interval duration varied from 81 (MAD 51) to $117 \mathrm{~min}$ (MAD 81), and again, there was no significant relation to the sampling period or to the duration of the experiment (Kolmogorov Smirnov test, $P>0.005$; Table 2).

The average egg production rate day $^{-1}$ as calculated from the eggs produced during the incubation (see Methods) varied from 18 (SD 17) to 28 (SD 26) eggs female day $^{-1}$ (Table 2). The highest average egg production rate of spawning females was 31 (SD 26), and the lowest rate was
23 (SD 16) eggs spawning female ${ }^{-1}$ day $^{-1}$. The highest individual egg production rate during our experiments was 132 eggs female ${ }^{-1}$ day $^{-1}$.

\section{Discussion}

According to light microscopy, gonad structure and oocyte development processes in A. clausi are similar to those described in other calanoid copepod species (e.g. Calanus

Table 2 Reproduction of Acartia clausi during incubation experiments

\begin{tabular}{clllllll}
\hline Date & $\mathrm{D}(\mathrm{h})$ & $N_{\mathrm{F}}$ & $\mathrm{F}(\%)$ & Interval (min) & $\mathrm{CS}\left(n \mathrm{clutch}^{-1}\right)$ & $\mathrm{EPR}_{\left(n \mathrm{f}^{-1} \mathrm{day}^{-1}\right)}$ & $\mathrm{EPR}_{\mathrm{SF}}\left(n \mathrm{f}^{-1} \mathrm{day}^{-1}\right)$ \\
\hline 10.4. & 12 & 108 & 82 & $89(54)$ & $3(2)$ & $23(20)$ & $27(19)$ \\
11.4. & 12 & 63 & 86 & $91(53)$ & $2(1)$ & $20(15)$ & $24(14)$ \\
2.5. & 8 & 120 & 80 & $81(51)$ & $2(1)$ & $18(17)$ & $23(16)$ \\
3.5. & 8 & 120 & 78 & $117(71)$ & $2(1)$ & $21(20)$ & $27(20)$ \\
4.5. & 8 & 120 & 90 & $83(48)$ & $2(1)$ & $28(26)$ & $31(26)$ \\
\hline
\end{tabular}

Presented are the date of the experiment, the duration of the incubation (D), the number of females in the experiment $\left(N_{\mathrm{F}}\right)$, the percentage of females, which spawned during the observation period $(\mathrm{F})$, the median interval between two spawning events, the median clutch size (CS), the daily total egg production rate (EPR), and the egg production rate of spawning females (EPR $\left.{ }_{\mathrm{SF}}\right)$. In brackets, the median absolute deviation (MAD) is given for clutch size and inter-spawning interval, and the standard deviation (SD) is given for mean EPR and EPR 
finmarchicus (Hilton 1931; Niehoff and Hirche 1996), Labidocera aestiva (Blades-Eckelbarger and Youngbluth 1984), Temora stylifera (Razouls 1974), Centropages typicus (Arnaud et al. 1982), Pseudocalanus spp. (Niehoff 2003)). Only the ovary morphology showed differences within the genus Acartia and to other copepod taxa. In A. clausi the ovary was w-shaped with two separated tips pointing backwards. Norrbin (2001) described the ovary of immature females of another Acartia species, A. longire$m i s$, as a shallow $\mathrm{U}$ with two tips pointing forward. In other copepod taxa such as e.g. Labidocera, Calanus, Temora and Centropages, the ovary is uniformly pear-shaped (Hilton 1931; Razouls 1974; Arnaud et al. 1982; BladesEckelbarger and Youngbluth 1984). These morphological differences, however, did not mirror differences in the location of early development processes. As in all other copepod species, the mitotic division of oogonia, which enter the prophase of the first maturation division and become oocytes, and their first growth all take place in the ovary. During further development, the oocytes are situated in the diverticula. These development processes are characterised by the formation of yolk (vitellogenesis), cell growth and incorporation of lipid vesicles. In crustaceans, two phases of vitellogenesis are distinguished (see Harrison 1990 for review). Vitellogenesis 1 is comparably slow and depends on an endogenous yolk source, while vitellogenesis 2 is characterised by rapid accumulation of yolk, which is provided by an extra-ovarian source (Harrison 1990). As in other copepod species (Centropages typicus (Arnaud et al. 1982), Calanus spp. (Niehoff and Hirche 1996; Niehoff 1998), Pseudocalanus spp. (Niehoff 2003)), these processes are also visible in A. clausi. The morphological characters of the oocytes suggest that OS 1 and OS 2 undergo vitellogenesis 1 since there were no indications of an exogenous contribution to the yolk formation, such as large follicle cells or invaginations (Arnaud et al. 1982; Blades-Eckelbarger and Youngbluth 1984). OS 3 is associated with vitellogenesis 2 indicated by rapid accumulation of many yolk and lipid droplets. Some copepod species develop large follicle cells in this development stage (Labidocera aestiva (Blades-Eckelbarger and Youngbluth 1984), Calanus finmarchicus (Niehoff and Hirche 1996), C. glacialis, C. hyperboreus (Niehoff 1998)). Follicle cells were also found in Undinula vulgaris, Euchaeta marina, Centropages furcatus, $C$. velifurcatus, Acartia tonsa and Pleuromamma xiphias (Eckelbarger and Blades-Eckelbarger 2005), and Blades-Eckelbarger and Youngbluth (1984) suggest that this indicates a material uptake from the haemolymph. In A. clausi follicle cells were small, like in Pseudocalanus spp. (Niehoff 2003). By trans-electronmicroscopy, Arnaud et al. (1982) have shown for Centropages typicus that exogenous material is incorporated into the oocyte by pinocytotic activity, which might also be the case in A. clausi. Ianora and Scotto di Carlo (1988) found " a fluid-like mass bathing the gonads of A. clausi" during winter. The authors suggest that this material plays an active role in vitellogenesis in certain periods of year as it coincides with high egg production rates. In our study conducted during spring, females did not contain such mass, although egg production was in the range of maximum rates measured at Helgoland Roads (Halsband and Hirche 2001). In OS 4, the nucleus was dissolved and the chromosomes were situated on the equatorial plate of the first maturation division. In this stage, oocytes are typically released in calanoid copepods (Calanus spp. (Harding 1963; Niehoff 1998), Centropages typicus (Arnaud et al. 1982), Epilabidocera amphitrites (Park 1966), Labidocera aestiva (Blades-Eckelbarger and Youngbluth 1984), Metridia gerlachei (Niehoff et al. 2002), Pseudocalanus spp. (Niehoff 2003)).

The oocyte number, stages and alignment in the gonads of calanoid copepods differ considerably, and this seems to reflect the mode of reproduction. The gonads of A. clausi resemble those of Labidocera aestiva. They are characterised by the occurrence of all oocyte development stages including intermediate forms, which indicates that oocyte development is a continuous process in these species (Blades-Eckelbarger and Youngbluth 1984). In A. clausi, only few oocytes were in the same stage, and hence, only few oocytes reach OS 4 simultaneously. Accordingly, the clutches were usually small, with one to five eggs. In contrast to other species, not all OS 4 are released during a spawning event but some may remain in the diverticula. Hence, the appearance of the gonads does not change visibly due to recent spawning. In the diverticula of Pseudocalanus spp. (Niehoff 2003), at the maximum two batches of oocytes of different development stages are present at a particular time. Younger oocytes (OS 2) are situated in a batch close to the ovary, whereas advanced oocytes (OS 3 or OS 4) fill the diverticula throughout the length of the gonad and reach maturity simultaneously. All mature oocytes are released during a spawning event, and the diverticula appear empty thereafter (Niehoff 2003). In other copepod taxa such as Calanus (Niehoff 1998; Razouls et al. 1991), Centropages (Arnaud et al. 1982), and Temora (Razouls 1974), the oocytes in the diverticula increase in size and development stage in a dorso-ventral direction. During spawning all mature oocytes are released, and then the adjacent dorsal layer begins final development (Niehoff and Hirche 1996). It is thus possible to predict the timing of spawning from the occurrence of OS 4 and the clutch size from the number of oocytes in final development processes (OS 3 or OS 4, Niehoff and Runge 2003) whereas it is not in A. clausi due to the fact that some OS 4 may remain in the diverticula.

In our study, egg production calculated for spawning females kept at high food concentration was 23-31 eggs 
female $^{-1}$ day $^{-1}$. This is in the range of in situ-egg production rates of $A$. clausi measured by Halsband and Hirche (2001) during spring at Helgoland Roads. Clutch size and spawning frequency of $A$. clausi have not yet been described precisely, however, it has been observed that this species releases eggs throughout the day (Dagg 1977; Halsband and Hirche 2001). Our study shows that A. clausi deposits in small clutches of one to five eggs (median of two eggs clutch $^{-1}$ ) at intervals usually not longer than $1.5 \mathrm{~h}$. Hence, reproductive traits of $A$. clausi differ considerably from those of other copepod species of the southern North Sea (Centropages typicus, C. hamatus, Temora longicornis) which are capable to produce much larger clutches ( $>80 \mathrm{eggs} \mathrm{clutch}^{-1}$ ) but at lower frequencies (Halsband and Hirche 2001). At Helgoland Roads in the North Sea maximum daily egg production rates of the other species were higher than that of A. clausi (Halsband and Hirche 2001). Halsband and Hirche (2001) reported a maximum individual rate of 55 eggs female $^{-1}$ day $^{-1}$. Bunker and Hirst (2004) summarized mean egg production rates of Acartia spp. (their Fig. 5), and found rates $>100$ eggs female ${ }^{-1} \mathrm{~d}^{-1}$. In our experiments, one female produced 76 eggs within a 12-h incubation. Projected for $24 \mathrm{~h}$, this yields a production of 132 eggs female ${ }^{-1}$ day $^{-1}$. This was exceptionally high; however, $12 \%$ of all females incubated produced 50 or more eggs day ${ }^{-1}$ confirming that A. clausi females are physiologically capable of reaching as high rates as those species spawning large clutches. Hence, the differences in gonad morphology and reproductive traits do not point to lower fecundity. It is possible, that the development of few oocytes at a time allows reacting faster to changing food conditions compared to species spawning large clutches. However, if and how the evolution of these traits is advantageous for the survival of A. clausi in its ecological niche would need to be investigated in future.

Acknowledgments We wish to thank the scientists and the staff at the Biologische Anstalt Helgoland for their support during the sampling periods. Thanks are especially due to the captain and the crew of the research boat "Aade". The experiments presented in this manuscript comply with the current laws of Germany. This publication is part of the diploma thesis by S. Eisfeld at the University of Bremen.

\section{References}

Arnaud J, Brunet M, Mazza J (1982) Etude de ĺovogenèse chez Centropages typicus (Copepoda, Calanoida). Reprod Nutr Dév 22:537-555

Blades-Eckelbarger PI, Youngbluth MJ (1984) The ultrastructure of oogenesis and yolk formation in Labidocera aestiva (Copepoda: Calanoida). J Morphol 179:33-46

Bunker AJ, Hirst AG (2004) Fecundity of marine planktonic copepods: Global rates and patterns in relation to chlorophyll a, temperature and body weight. Mar Ecol Prog Ser 279:161-181
Dagg M (1977) Some effects of patchy food environment on copepods. Limnol Oceanogr 22:99-107

Donaghay PL, Small LF (1979) Long-term food modification by Acartia clausi: a preliminary view. Mar Biol 52:129-136

Dutz J (1998) Repression of fecundity in the neritic copepod Acartia clausi exposed to the toxic dinoflagellate Alexandrium lusitanicum: relationship between feeding and egg production. Mar Ecol Prog Ser 175:97-107

Eckelbarger K, Blades-Eckelbarger P (2005) Oogenesis in calanoid copepods. Invertebr Reprod Dev 47:167-181

Engel M, Hirche HJ (2004) Seasonal variability and inter-specific differences in hatching of calanoid copepods resting eggs from sediments of the German Bight (North Sea). J Plankton Res 26:1083-1093

Fransz HG, Colebrook JM, Gamble JC, Krause M (1991) The zooplankton of the North Sea. Netherl J Sea Res 28:1-52

Halsband C, Hirche H-J (2001) Reproductive cycles of dominant calanoid copepods in the North Sea. Mar Ecol Prog Ser 209:219229

Harrison KE (1990) The role of nutrition in maturation, reproduction and embryonic development of decapod crustaceans: a review. J Shellfish Res 9:1-28

Harding JP (1963) The chromosomes of Calanus finmarchicus and $C$. helgolandicus. Crustaceana 6:81-88

Hay S (1995) Egg production and secondary production of common North Sea copepods: field estimates with regional and seasonal comparisons. ICES J Mar Sci 52:315-327

Hickel W (1975) The mesozooplankton in the wadden sea of Sylt (North Sea). Helgoländer wiss Meeresunters 27:254-262

Hilton IF (1931) The oogenesis of Calanus finmarchicus. Quart J Micr Sc 74:193-222

Husemann E (1992) Bestandsaufnahme und Larvenentwicklung der im Helgoländer Plankton auftretenden Polychaeten und Polychaetenlarven. Ordnungen: Phyllodocida, Oweniida, Terebellida, Sabellida und Familien mit unsicherer Ordnungszugehörigkeit. $\mathrm{PhD}$ Thesis, Ruhr-University Bochum, Germany

Ianora A, Buttino I (1990) Seasonal cycles in population abundances and egg production rates in the planktonic copepods Centropages typicus and Acartia clausi. J Plankt Res 12:473-481

Ianora A, Scotto di Carlo B (1988) Observations on egg production rates and seasonal changes in the internal morphology of Mediterranian populations of Acartia clausi and Centropages typicus. Hydrobiologia 167/168:247-253

Ianora A, Poulet SA, Miralto A, Grottoli R (1996) The diatom Thalassiosira rotula affects reproductive success in the copepod Acartia clausi. Mar Biol 125:279-286

Karnovsky MJ (1965) A formaldehyde-glutaraldehyde fixative of high osmolarity for use in electron microscopy. J Histochem Cytochem 12:219-221

Mayzaud P, Tirelli V, Bernard JM, Roche-Mayzaud O (1998) The influence of food quality on the nutritional acclimation of the copepod Acartia clausi. J Mar Sci 15:483-493

Niehoff B (1998) The gonad morphology and maturation in Arctic Calanus species. J Mar Syst 15:53-59

Niehoff B (2003) Gonad morphology and oocyte development in Pseudocalanus spp in relation to spawning activity. Mar Biol 143:759-768

Niehoff B, Hirche HJ (1996) Oogenesis and gonad maturation in the copepod Calanus finmarchicus and the prediction of egg production from preserved samples. Polar Biol 16:601-612

Niehoff B, Runge JA (2003) A revised methodology for prediction of egg production of the marine planktonic copepod Calanus finmarchicus from preserved samples. J Plankton Res 25:15811587

Niehoff B, Schnack-Schiel SB, Cornils A, Brichta M (2002) Reproductive activity of two dominant antarctic copepod species, 
Metridia gerlachei and Ctenocalanus citer, in late autumn in the eastern Bellingshausen Sea. Polar Biol 25:583-590

Norrbin F (2001) Ultra-structural changes in the reproductive system of overwintering females of Acartia longiremis. Mar Biol 139:697-704

Park TS (1966) The biology of a calanoid copepod Epilabidocera amphitrites McMurrich. La Cellule 66:129-251

Plate S (1992) Untersuchungen zum zeitlichen Auftreten, zur Abundanz und Entwicklung meroplanktischer Polychaetenlarven im Gebiet Helgoland Reede. Ordnungen: Orbiniida, Spionida und Capitellida. PhD Thesis, Ruhr-University Bochum, Germany

Plourde S, Runge JA (1993) Reproduction of the planktonic copepod Calanus finmarchicus in the Lower St. Lawrence Estuary: relation to the cycle of phytoplankton production and evidence for a Calanus pump. Mar Ecol Prog Ser 102:217-227

Prestidge MC, Harris RP, Taylor AH (1995) A modelling investigation of copepod egg production in the Irish Sea. ICES J Mar Sci 52:693-703
Razouls S (1974) Maturite sexuelle et fecondite chez les fermelles de Temora stylifera, copepode pelagique (Copepoda Calanoidea). Arch Zool Exp Gen 115:387-399

Razouls S, Nival S, Nival P (1986) La réproduction de Temora stylifera: ses implications anatomiques en relation avec le facteur „,nutrition”. J Plankt Res 8:875-889

Razouls S, Razouls C, Huntley M (1991) Development and expression of sexual maturity in female Calanus pacificus (Copepoda: Calanoida) in relation to food quality. Mar Biol 110:65-74

Tiselius P, Nielsen TG, Breuel G, Jaanus A, Korshenko A, Witek Z (1991) Copepod egg production in the Skagerrak during SKAGEX, May-June 1990. Mar Biol 111:445-453

Uye SI (1981) Fecundity studies of neritic calanoid copepods Acartia clausi Giesbrecht and $A$. steueri Smirnov: a simple empirical model of daily egg production. J Exp Mar Biol Ecol 50:255-271 